\title{
Land Suitability Evaluation Based on GIS in Landscape Planning of BeiJing Yanqing Sihai Town
} \\ ${ }^{1}$ Department of landscape architecture, Beijing University of Agriculture, Peking,Beijing \\ 102206,China ; \\ ${ }^{2}$ Beijing Rural Landscape Planning and Design Engineering Technology Center, Peking ,Beijing \\ 102206,China ; \\ ${ }^{3}$ Beijing Laboratory of Urban and Rural Ecological Environment, Peking ,Beijing 100083,China.

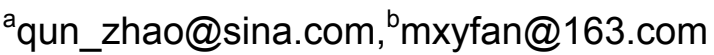

Keywords: GIS, land suitability evaluation, landscape.

\begin{abstract}
In modern landscape planning area, more and more high technology are combined with planning and design theory to solve practical problems.GIS provides a new method for landscape planning with its powerful spatial analysis function. GIS can increase feeling of planning results. GIS enables planners to accurately understandand grasp the natural landscape, to provide some new ideas in the landscape planning and landscape design. So analysis of elevation has been done based on GIS in landscape planning of Beijing Yanqing Sihai town.
\end{abstract}

\section{Introduction}

In twentieth Century 50, 60 years,American landscape planner MacHarg had a great influence on forming of GIS technology in his field. He carried on landscape planning through layer upon layer overlay of GIS. Then Elliot one of pioneers of landscape design education in Harvard University develop the technology to be one of the characteristics of landscape planning.

Planning mode of Layer upon layer overlay of GIS is developed in technology. Before appearing of computer, the process is finished with a transparent diaphragm. Sixty time metaphase, Harvard University professor Steinitz began to do this process by computer. At last overlay become a basic function of GIS. It can be completed in general commercial GIS software.

\section{Slop Analysis of GIS Application in Landscape Planning}

With fast and accurate spatial information acquisition ability, powerful function of dynamic prediction, comprehensive analysis of region and highly customizable of GIS, through obtaining multiple information and data on valley, digital elevation model is built. Using slope analysis, GIS provides basic dependencies for rational layout and a full range of information services for planning an decision making. So planners can be more efficient and accurate understanding of valley ecological and environmental conditions.

According to valley terrain features, using theory and technology of GIS, using slope analysis of GIS, valley topography and landform condition can be evaluated. In landscape ecological planning of valley, slope analysis technique are mainly applied. At the same time, various related operations on spatial data of various types and evaluation of valley ecological system are made. 


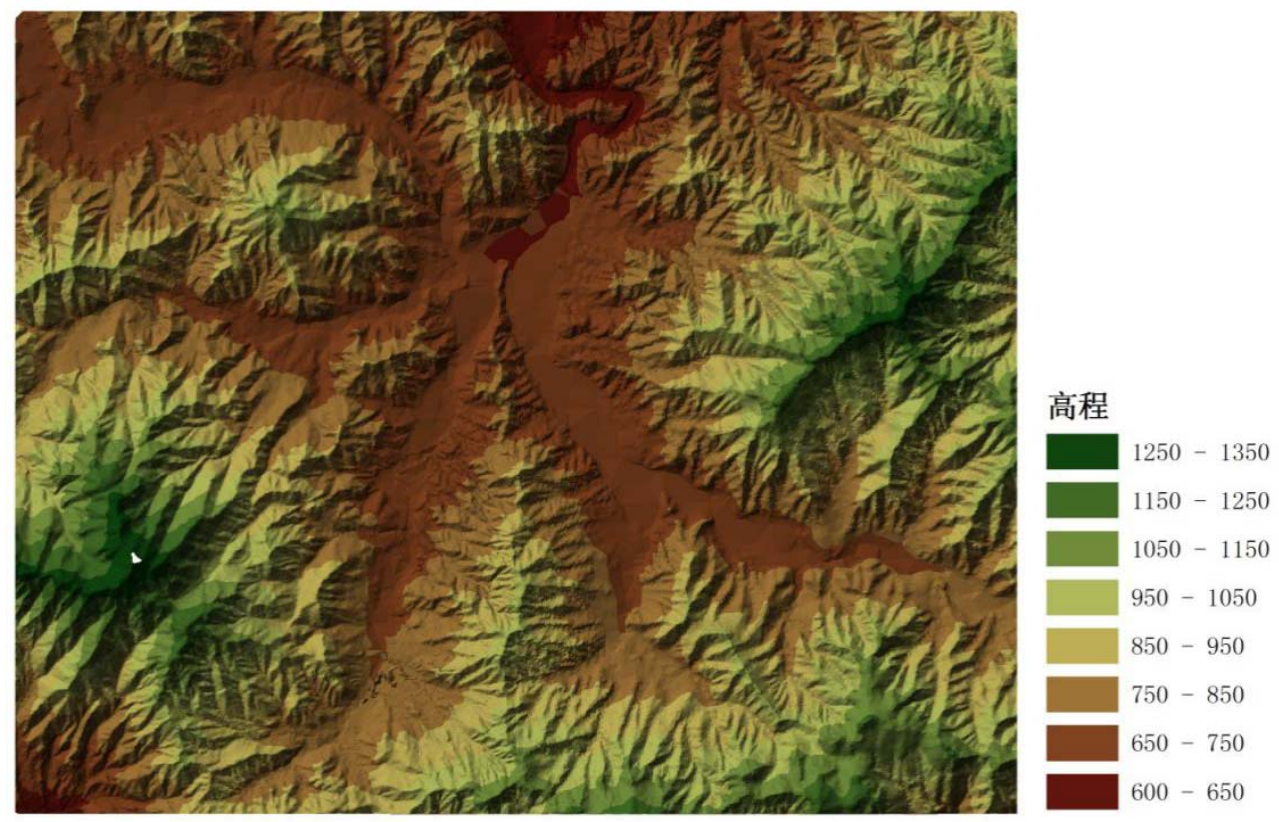

Figure 1.Analysis of elevation

Using digital elevation model based on GIS simulation, contour line of selected region of mountain is drawn automatically. At the same time, the data of analysis can be formed in the database. Designers can retrieve data on multiple conditions according to actual needs. In flat slope and gentle slope, the terrains is relatively flat and open, architectural layout is free, building can obtain sunshine and good landscape view toward. Arrangement of road layout also can be made ideal, generally earthwork is not big. The slope is greater, the geological stability of mountain areas is poor, the possibility of soil erosion is greater, it is easy to happen collapse, erosion, run off.

The slope of the planning area can be extracted by ArcGIS spatial analysis.After the reclassification, slope map can be obtained by the property data statistics analysis. Slope is a necessary condition for accurate and efficient analysis of terrain. The human is often limited in the field of the slope in the land utilization, the slope of the terrain is greater, the impact to design and construction will be more greater.

According to the research, it is shown that in the construction of the road, the water supply engineering and the heating engineering, the cost of the engineering technology is significantly higher than that of the plain area.And the slope of the terrain can increase the surface area, so as to increase the length of the road.
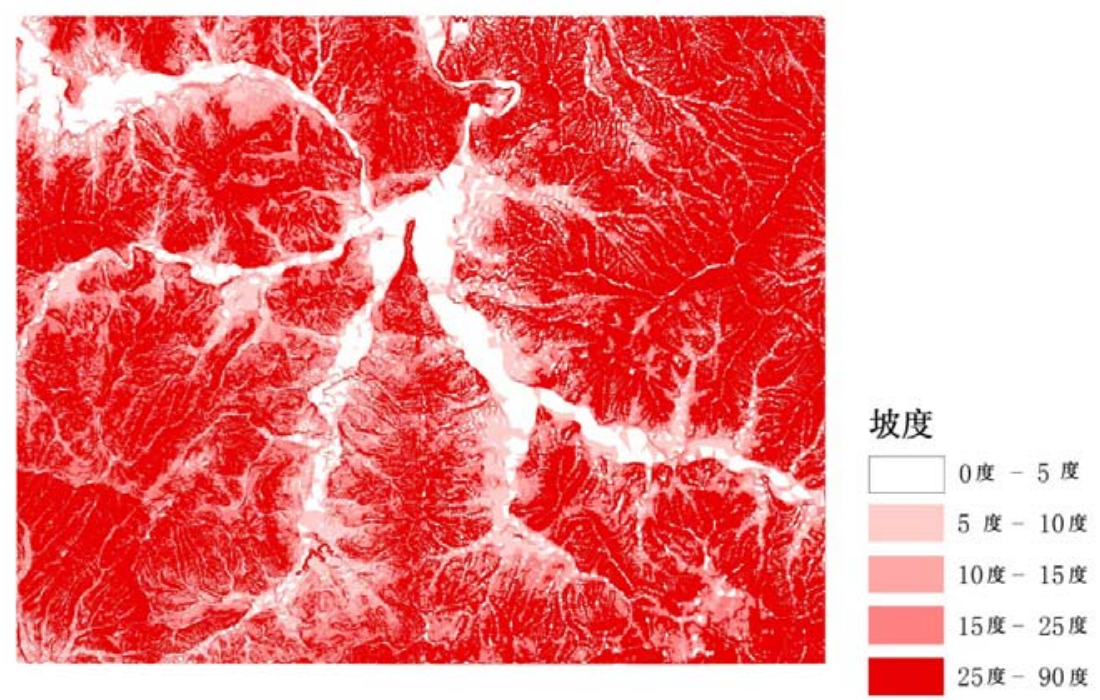

Figure 2 Slope Figure 
Thus, the slope of the terrain is a very important factor for planning, construction projects .To this end, according to the scale of the planning area of the mainland establish the level of the scale of planning suitability classification.

\section{Suitability Evaluation of Land Tape}

According to Table1, the weight values are added to each factor.The comprehensive numerical value of ecological suitability is calculated by the following formula:

$$
S_{i j=} \sum W(k) C_{i j}(k)
$$

$\mathrm{S}$ is comprehensive numerical value; $\mathrm{k}$ is Influencing factors for the evaluation of the $\mathrm{K}$; $\mathrm{W}$ is the Weight of an ecological factor; $\mathrm{C}$ is Indicated suitability grade; $\mathrm{i} 、 \mathrm{j}$ is grade number.

Table 1Classification of ecological adaptability

\begin{tabular}{|c|c|c|c|}
\hline Evaluation factors & classification criteria & Single factor score & Weight \\
\hline \multirow[t]{5}{*}{ Water } & $>100 \mathrm{~m}$ & 9 & \multirow[t]{5}{*}{0.28} \\
\hline & $70-100 m$ & 7 & \\
\hline & $50-70 m$ & 4 & \\
\hline & $30-50 \mathrm{~m}$ & 2 & \\
\hline & $<30 \mathrm{~m}$ & $\mathbf{0}$ & \\
\hline \multirow[t]{3}{*}{ Elavation } & $<\mathbf{5 0 m}$ & 8 & \multirow[t]{3}{*}{0.29} \\
\hline & $50-100 \mathrm{~m}$ & 3 & \\
\hline & $>100 \mathrm{~m}$ & 1 & \\
\hline \multirow[t]{4}{*}{ Slope } & $<\mathbf{8}^{\circ}$ & 8 & \multirow[t]{4}{*}{0.20} \\
\hline & $8-15^{\circ}$ & 5 & \\
\hline & $15^{8}-25^{\circ}$ & 2 & \\
\hline & $>\mathbf{2 5} 5^{\circ}$ & 1 & \\
\hline \multirow[t]{3}{*}{ Land use } & $\begin{array}{c}\text { Residential } \\
\text { industrial land, commercial } \\
\text { land, village, other land } \\
\end{array}$ & 8 & \multirow[t]{3}{*}{0.23} \\
\hline & forestry land & 3 & \\
\hline & special use area & $1 / 0$ & \\
\hline
\end{tabular}

To classy urban land with different suitability, comprehensive land ecological suitability distribution map is made.Adaptive degree increases with the color of the picture becoming light. 


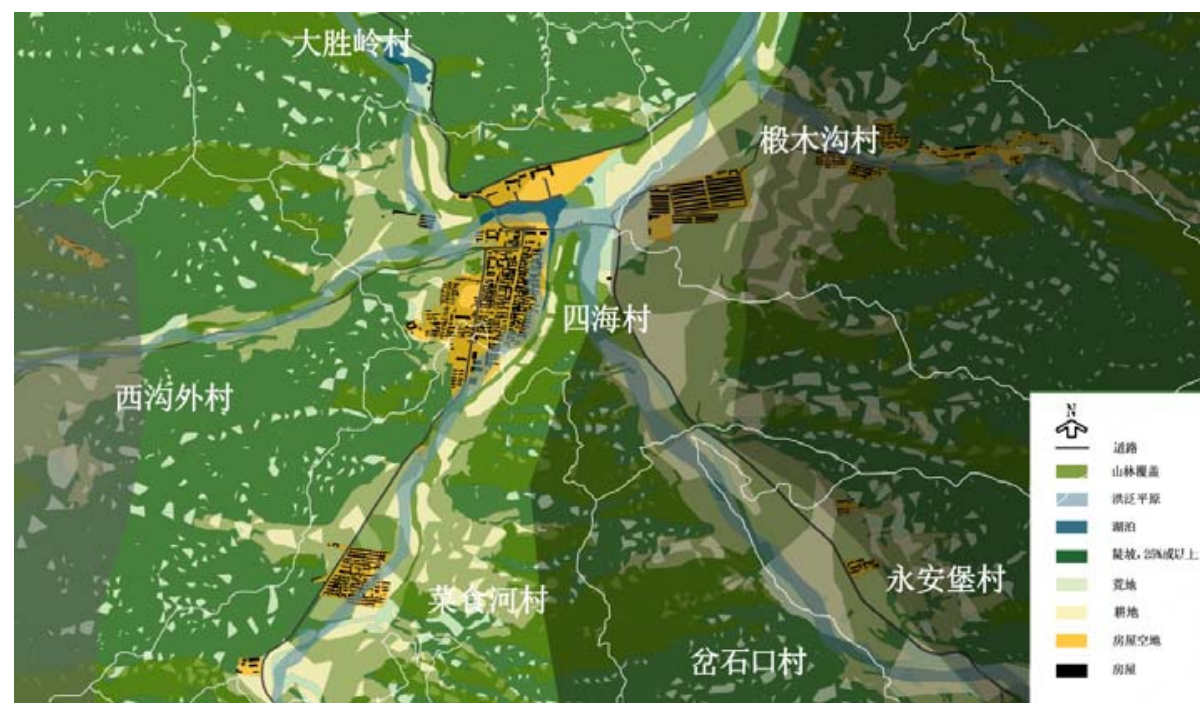

Figure3 Ecological adaptability

\section{Summary}

Put slope and aspect analysis function of GIS and DEM together, slope map are made. It can provide direct reference for field layout and selection of plants. Slope indicates a tilt of the local surface slope. It directly affect the size and strength of surface material flow and energy conversion. Slope is the important factor to restrict to spatial distribution of productive forces. Through slope distribution, combined with different thermal requirement of sun plants and shade plants, determine where plant is, agricultural and ecological planning carry out more scientific and reasonable. It can provide direct reference for field layout and selection of plants. It is the base for landscape planning.

\section{Acknowledgement}

Thanks to the support of two projects.

1.Research base construction project:The application of $3 \mathrm{~S}$ technology in the planning and construction of the Science Park of BeiJing Agricultural University,Project code:PXM2015_014207_000010

2.Beijing laboratory construction of urban and rural ecological environment project, Project code:PXM2015_014207_000014

\section{References}

[1]SIoan S W. A fast Algorithm for Constructing Delaunay Triangulations in the Plane. AndvancedEngineeringSoftware[J],1987.9,PP34-55.

[2]ChenJun,ZhaoRenliang,LiZhilin.Voronoi-based k-order Neighbor Relations for SpatialAnalysis.ISPRSJournal ofPhotogrammetryandRemoteSensing[J],2004.59,PP60-72.

[3]S.Hattori, K. Akimoto, C.Fraser, H. Imoto. Automated procedures with coded targets in industuial vision metrology. Photogramm- etricengineering and remote sensing [J], 2002.68 (5), PP441-446.

[4]Wu Lun, Zhang Jing, Liu Yu. Principles and Methods of Geographic Information System[M]. Beijing: Science Press, 2002. (in Chinese)

[5]Chai Hejun. The rock mass structure model and engineering application research of Xiluodu hydroelectric power station of Jinsha river[D].Chengdu: Chengdu University of Technology, 1999. (in Chinese)

[6]Hanna, Karen C., Culpepper, R. Brian, GIS in Site Design: New tools for Design Profession.New 
York: John Wiley\& Sons,Inc.1998.

[7]Forman ILT. Land Mosaics: The ecology of landscape and region. New York: Cambridge University Press, 1995.

[8]YuanFei. Application of GIS in urban landscape planning anddesign [D].Northwest Agriculture and Forestry University,2012.

[9]ZuoXiaoShan, MaXiaoYan, LiuYang.Application of GIS in rural landscape planning and protection[J]. Anhui Agricultural Sciences. 2009(14).

[10]HuangXingYuan, etc.Introduction to geographic information system,Beijing: Higher Education Press, 1989. 